\title{
EXPERIMENTAL TEST ON CONTROL POINTS MATERIALIZATION FOR THE STUDY OF VERTICAL MOVEMENTS OF SOIL AND ITS INTERACTIONS WITH GROUND WATER CONTENTS
}

\author{
L. Vittuari, G. Gottardi , M.A. Tini
}

\begin{abstract}
Department of Civil, Chemical, Environmental and Materials Engineering (DICAM). University of Bologna. Viale Risorgimento 2, 40136, Bologna. Italy. [luca.vittuari, guido.gottardi2, mariaalessandra.tini]@ unibo.it
\end{abstract}

Commission VI, WG VI/4

KEY WORDS: Benchmarks, Monumentation, Vertical movements, Measurement, Monitoring, Levelling, InSAR, Soil water content

\begin{abstract}
:
In the study of soil vertical movements, one of the techniques most commonly used is the spirit levelling, now flanked by satellite SAR interferometry and by the analysis of time series acquired through permanent GNSS stations.

The reliability of control points monuments varies depending both on the geological context and on the structure being representative of the investigated phenomenon. Often due to the high number of desired points or to the need of maintaining a specific areal distribution, they are fixed on existing structures (as in the common case of spirit levelling networks). This aspect is even more evident in the case of SAR interferometric analysis, where the permanent scatterers are identified on the basis of consistency in the radar response, but the points display movements measured by structures with different foundations at different depths.

Starting from repeated precision levelling measurements, we verified which is the order of magnitude of movements of control points characterized by shallow foundations in cohesive soils, observing their behaviours at different depths, under simple and very common conditions such as the presence of periods of drought or rainfall. The results point-out movements in the order of 3-7 mm in the first meter of depth occurred in a week, during the transition between the period of summer drought and the first rains.
\end{abstract}

\section{INTRODUCTION}

In soils characterized by very low altitudes above sea level or with respect to the height of the river banks, the geodetic monitoring of the elevations of the ground surface, or of dikes, is of great importance for flooding protection, or to prevent sea water and saline wedge ingression with its dire implications on agriculture and salinity of groundwater. For this reason in such geographical contexts, geodetic infrastructures - especially networks of spirit levelling benchmarks, periodically remeasured by public agencies, private consortia or directly from municipal technical offices - are often maintained.

In most cases it exists a kind of inverse correlation between the number and density of the control points and the quality of their monuments. In fact, it can be observed as the permanent GNSS stations, installed for geodynamical purposes, are typically rarely distributed over a region and they are generally materialized with care, often following international standards that guarantee a high stability and representativeness of the investigated areas, while in levelling networks, where the number of benchmarks is high, except for special cases, the points are often anchored to pre-existing buildings or concrete structures, not always characterized by deep foundations. Sometimes the benchmarks are anchored to really shallow structures, such as in the case of nail in a manhole, benchmark fixed to simple curbs or fencing walls, etc. Finally, if we consider the InSAR control points (e.g. Persistent Scatterers PS), they are chosen on the basis of the signal coherence between successive acquisitions, independently from their nature, therefore the huge number of measured points represents a mixture of soil movement information captured at completely different depths in the ground, depending from the foundations of the PS structures.

Moreover one source of noise in geodetic signals is random motion occurring within the connection of the geodetic instrument to the ground (Beavan J., 2005). Monument noise can results from processes such as soil swelling due to rainfall, freeze-thaw cycles, or in general to rock and soil weathering effects (Wyatt, 1989).

For points deeply anchored in the soil, or directly fixed to well preserved rocky outcrops, the monument noise is thought to follow an approximately random walk process. Random walk means that the expected value of the monument position relative to an initial position increases as the square-root of time, typically for a high quality geodetic monument: 0.3 $\mathrm{mm} / \mathrm{yr}^{1 / 2}$ (Johnson and Agnew, 2000). Concerning the monuments devoted to fix GNSS permanent stations to the ground, a large number of studies are available (e.g. deep or shallow drilled braced monuments, concrete pillars, thermopile, polar mast, etc.). As example UNAVCO published on line a useful comparison table of several solutions, in term of reliability, cost, people involved for realization, time required for installation, impact, etc. Less frequents are the studies devoted to asses the reliability of the control points belonging spirit levelling networks or InSAR analysis. In particular the reliability of monuments shallow fixed in the ground, so common in operational practice.

The evaluation of the accuracy of the observed movements and the verification of the stability of the control points used in levelling networks to constraint the origin of the heights is complicated and tedious, even under the best conditions. Therefore, the precision of vertical networks is generally 
confused with the precision obtained downstream of the least squares adjustment of the observations.

In order to maintain a high level of precision within polygons closures validation, the measurements are planned as quickly as possible within the entire levelling network, engaging a high number of surveying teams, if it necessary. In this way can be presumed the presence of homogeneous conditions throughout the network. But this feared temporal decorrelation can be a symptom of real fast movements in progress due to the sought phenomenon or simply it could be the lack of significance of control points due to a scarce benchmarks monumentation. In fact, the type of benchmark can change significantly along a levelling line. This variety is even more evident in the case of SAR PS.

\section{INSTRUMENTS AND DESIGN OF EXPERIMENTAL TESTS}

Rainfall and water table variations may have a significant influence on deformation measurements. Typically rainfall induces in fine-grained soils a step-like deformation in very shallow layers. Vertical and horizontal movements could be observed and the direction may change to some extent, according to the amount of rainfall (Dal Moro and Zadro, 1998). Other aspects that could be considered are thermal expansion and influence of gravity changes due to hydrological cycles within the soil (Romagnoli et Al., 2003). As an example of the estimated influence, the yearly vertical variation induced by thermal expansion in bedrock or soil can be as small than 0.5 $\mathrm{mm}$ (Dong, et $\mathrm{Al}, 2002$ ). Anyway the long-period records suggest that near-surface weathering is the dominant influence on monument motion (Wyatt, 1989).

In particular our attention focused on the response of soils with a sensitive response to the relevant water content (mainly clay and silt), characteristic of quaternary alluvial sediments of Eastern part of the Po Valley (Pianura Padana), Northern Italy, or of pliocenic gentle slopes of the adjacent hillside.

In a previous experiment the intra-site motions and monument instabilities were estimated at Medicina ITRF co-location site (close to Bologna), considering deep founded monuments within cohesive soils starting from co-located GPS permanent stations and terrestrial high precision measurements (Sarti et al., 2013).

This further experimental test aims at providing quantitative evidence about the level of representativeness of shallow founded control points.

For this reason we focused our attention on the first five meters of thickness. In a small test field characterised by mainly clayey soil down to 7-10 m, with rare interpositions of silt and silty sand, a set of levelling benchmarks founded respectively at 0.3 $\mathrm{m}, 2.0 \mathrm{~m}, 3.5 \mathrm{~m}$ and $5.0 \mathrm{~m}$ from the soil surface were installed. This set of benchmarks was composed by inner metal bars coated with external PVC tubes, in order to avoid the possible dragging effects caused by soil motion to the inner measuring rods (Figure 1).

A knob fixed in a structure founded at $10 \mathrm{~m}$ depth was used as reference benchmark. The benchmarks were connected vertically through a redundant measurement scheme, with a set of other points fixed in old houses masonry and studs fixed in the concrete casting made for access ramps to the buildings.

As the water table is normally located during the year sufficiently distant from soil surface $(\approx 7.5 \mathrm{~m})$, the measured effects in the upper unsaturated soil layers were separated from those induced by possible water table changes.
The set of benchmarks located at different known depths has been installed in a field covered by grass, in order to avoid interaction with the natural soil imbibition by rain.

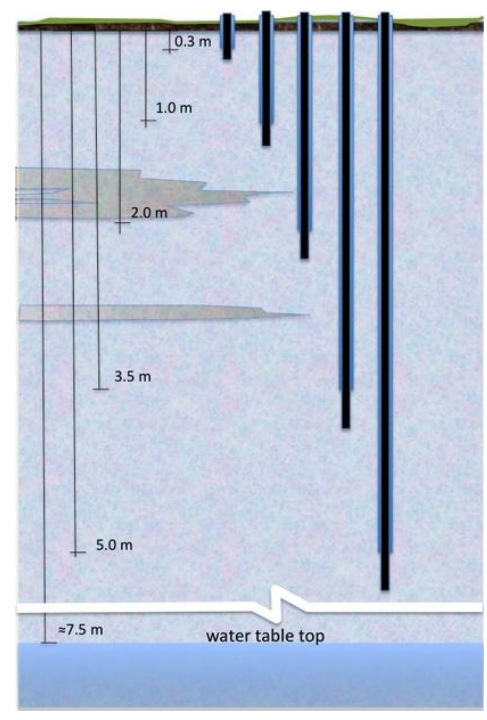

Figure 1. Scheme of vertical benchmarks used to monitor rainfall effect over the first five meters of soil thickness.

The overall distances between the test points and the reference benchmark were maintained within one hundred meters, theoretically suitable for the adoption of a small high precision spirit levelling network. However, considering the need of repeating measurements after rain, the expected soft soil conditions required the design of a more reliable measurement methodology. It was thus decided to adopt an integration of two levelling techniques: spirit and differential trigonometric levelling. This solution allowed a great flexibility in overcoming obstacles, maintaining the desired level of precision, even in condition of muddy ground. In fact thanks to the longer operating range of the total stations, compared to digital levels, it was possible to keep the key stations on solid soil, leaving to the spirit levelling the role of connecting the benchmarks belonging to the same cluster.

In order to maintain the precision of heights determinations within few tenths of a mm for each campaigns through the trigonometric levelling, we used two metal rods of calibrated heights, equipped with a planar heel surface at the toe, and bayonet connectors for precision retro-reflecting prisms at the top. For the measurements were used two high-end robotics total stations (Leica TCA2003 and Leica TS30), both characterized by a nominal angular precision of \pm 0.5 " and an accuracy of $\pm(1 \mathrm{~mm}+1 \mathrm{ppm})$ and $\pm(0.6 \mathrm{~mm}+1 \mathrm{ppm})$ respectively, in measuring slope distances. Being sight lines almost horizontal the high precision is mainly maintained by zenithal angles reliability.

Whereas for each station the slope distances $D_{1}$ and $D_{2}$ and considering symmetric the coefficient of refraction $\mathrm{k}$ for the two angular readings $\left(\varphi_{1}, \varphi_{2}\right)$ to the prisms, the difference in elevation (Figure 2 ) is given by:

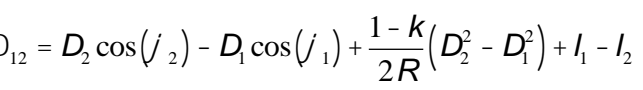

Applying the rule of propagation of variance to (1) it can be observed that up to $200-250 \mathrm{~m}$ between points the two techniques are comparable, with respect to the usual tolerance used in public works for precision spirit levelling $\pm 2(\mathrm{~mm}) \sqrt{ } \mathrm{d}(\mathrm{km})$. 


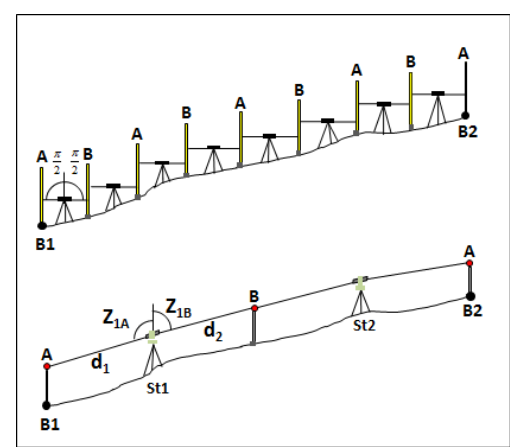

Figure 2. Scheme of spirit levelling and differential trigonometric levelling.

Therefore the field test (Figure 3) was overall composed by:
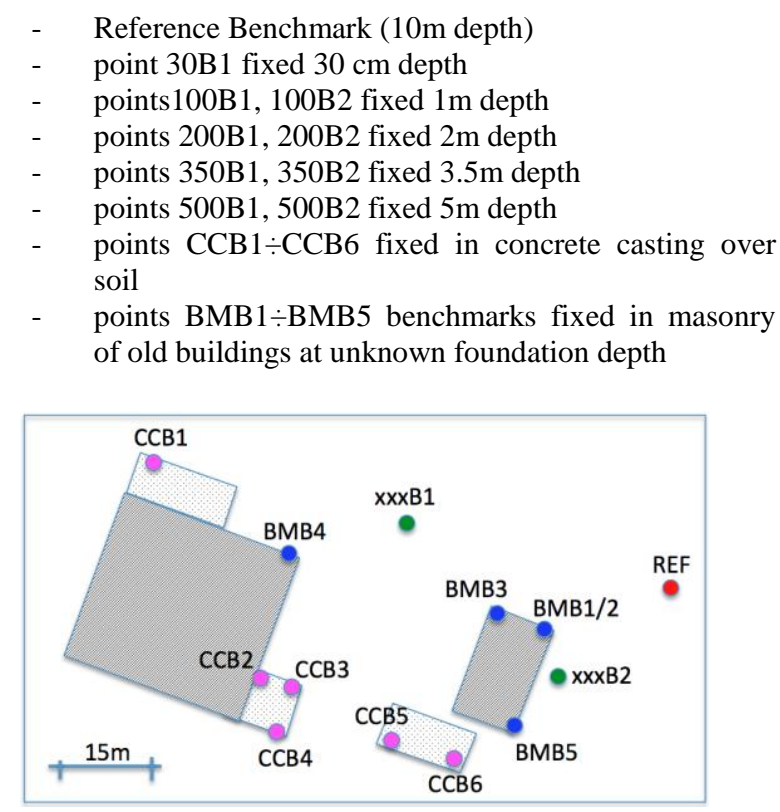

Figure 3. Scheme of the type of control points: red dot reference benchmark, blue dots benchmarks on building masonry, purple dots benchmark on concrete castings, green dots benchmarks installed at known depth $(30 \mathrm{~cm}, 1 \mathrm{~m}, 3.5 \mathrm{~m}, 5 \mathrm{~m})$ in a grassy field.

\subsection{Measurements and Results}

The experiment was conducted for about three months, starting from the end of the dry season through the rainy one.

During this period levelling measurements were carried out approximately every one/two weeks, obtaining a set of 11 repetitions.

For each epoch, least square adjustment was performed using simultaneously both the height differences measured by spirit levelling, both the ones obtained by (1), using appropriate weights strategies for the two techniques. As mentioned before, the combined use of both surveying methods allowed obtaining good and reliable results despite of conditions of muddy ground, obstacles presence and short measuring time. Indeed the network repetitions showed an average redundancy greater than 5 and a posteriori confidence intervals $(95 \%)$ for the estimated unknown elevations at few tenths of mm level.

In order to investigate the effect of rainfall on benchmarks elevation, the height differences measured between two contiguous epochs were plotted over the distribution of rainfall amounts, recorded by a rain gauge installed close to the test field.

In order to compare the behaviour of different contexts of materialization, the benchmarks were grouped according to the different type of installation in plotting results.

An evident correlation between vertical movements and peaks of the rainfall for relatively shallow monumentations can be observed, several points show delay of few days in the response of soil to water imbibition, partially masked by the step of measures sampling with respect to the response of soil. As expected, benchmarks fixed in gradually greater depths show a more suitable behaviour.

In particular, figure 6 , compares the vertical movements of adjacent benchmarks at different depths and shows that their movements are significantly different. In this regard it should be noticed also the remarkable magnitude of rise $(7 \mathrm{~mm})$ measured by the benchmark at depth $0.3 \mathrm{~m}$ within a week, observed during the transition from summer drought and the first rain.

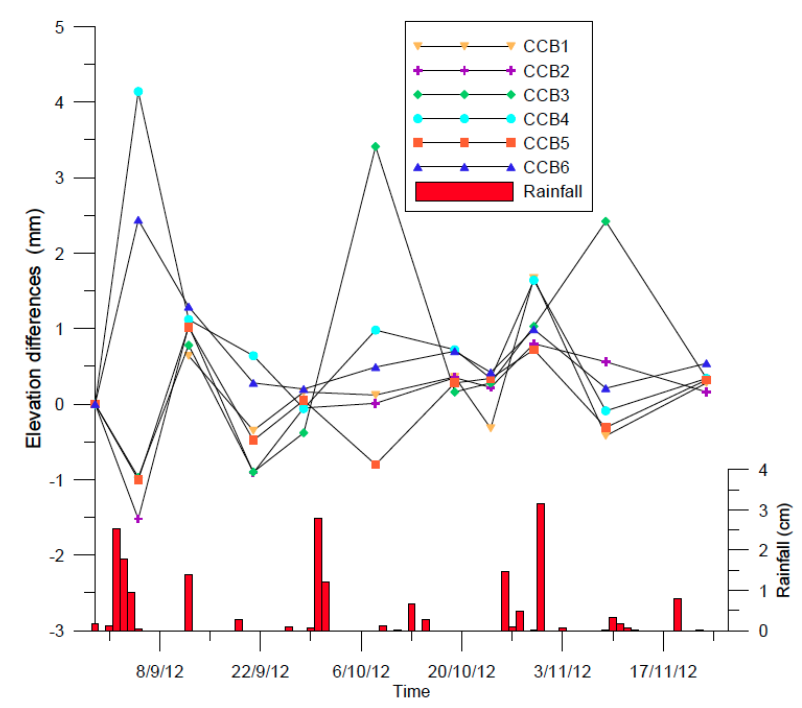

Figure 4. Elevation differences between two contiguous measurement epochs $\left(\mathrm{h}_{\mathrm{ti}}-\mathrm{h}_{\mathrm{ti}-1}\right)$ for benchmarks fixed in concrete casting over soil.

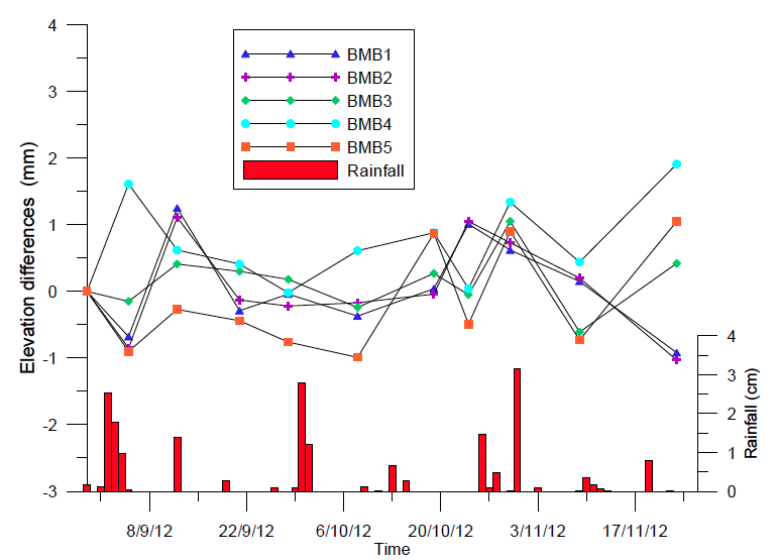

Figure 5. Elevation differences between two contiguous measurement epochs $\left(\mathrm{h}_{\mathrm{ti}}-\mathrm{h}_{\mathrm{ti}-1}\right)$ for benchmarks fixed in masonry of old buildings at unknown foundation depth. 


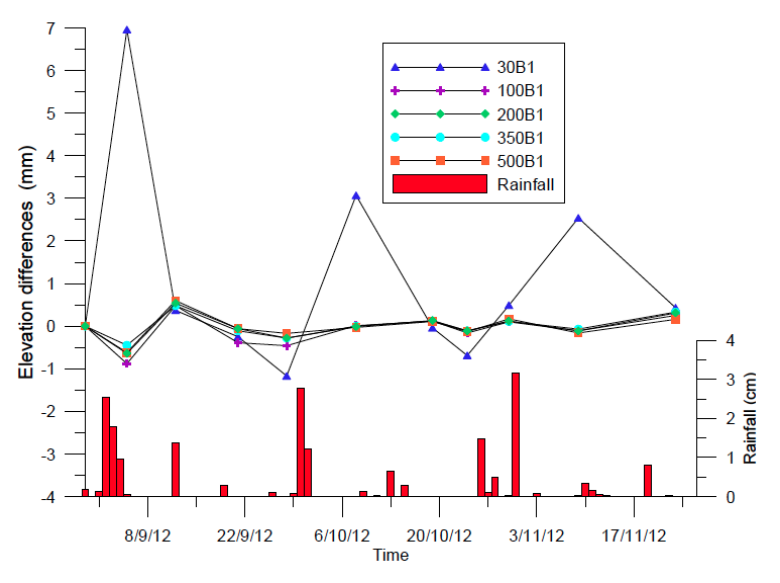

Figure 6. Elevation differences between two contiguous measurement epochs $\left(\mathrm{h}_{\mathrm{ti}}-\mathrm{h}_{\mathrm{ti}-1}\right)$ for benchmarks fixed in soil: comparison between the behaviours of neighbour benchmarks founded at different depths.

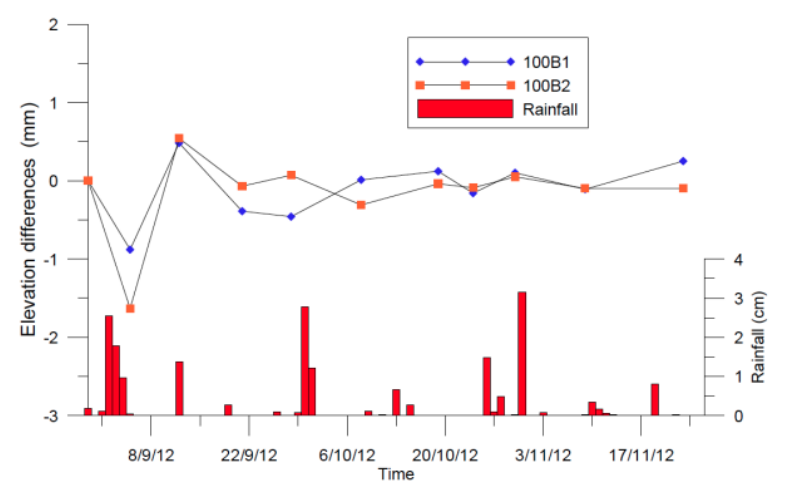

Figure 7. Elevation differences between two contiguous measurement epochs $\left(\mathrm{h}_{\mathrm{ti}}-\mathrm{h}_{\mathrm{ti}-1}\right)$ for benchmarks fixed in soil at $1 \mathrm{~m}$ depths.

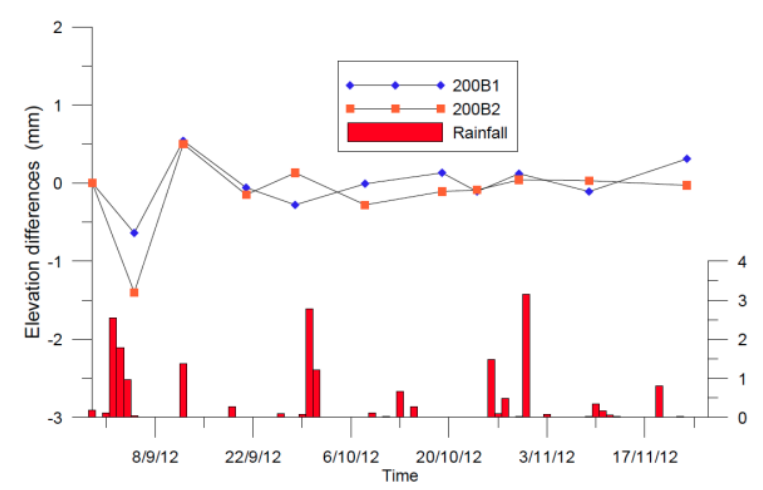

Figure 8. Elevation differences between two contiguous measurement epochs $\left(\mathrm{h}_{\mathrm{t} i}-\mathrm{h}_{\mathrm{t}-1}\right)$ for benchmarks fixed in soil at $2 \mathrm{~m}$ depths.

If we consider instead of single rainfall events, the cumulate rainfall we can quantify the overall changes in elevation observed in the period of few months (August-November).

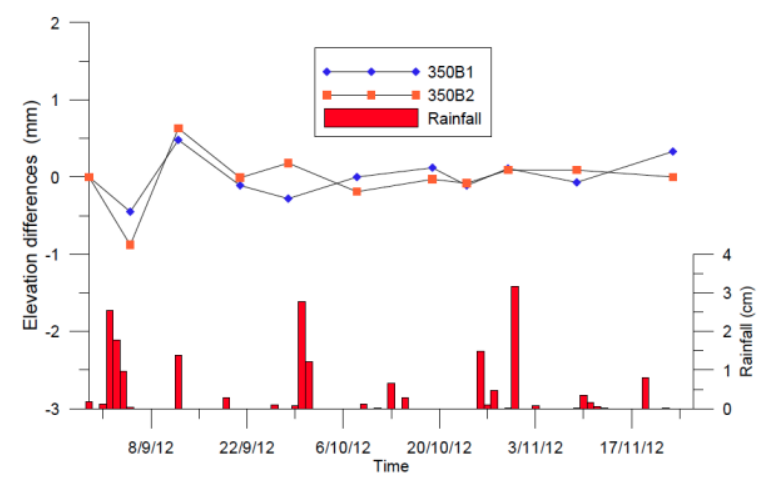

Figure 9. Elevation differences between two contiguous measurement epochs $\left(\mathrm{h}_{\mathrm{ti}}-\mathrm{h}_{\mathrm{t} \mathrm{i}-1}\right)$ for benchmarks fixed in soil at $3.5 \mathrm{~m}$ depths.

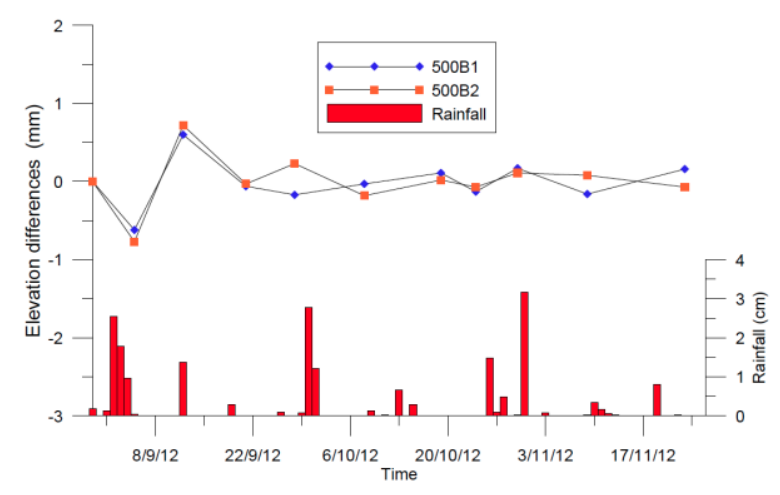

Figure 10. Elevation differences between two contiguous measurement epochs $\left(\mathrm{h}_{\mathrm{ti}} \mathrm{h}_{\mathrm{ti}-1}\right)$ for benchmarks fixed in soil at $5 \mathrm{~m}$ depths.

Besides the benchmarks properly installed at known depths, the overall movements shown by control points fixed in existing structures appear to be substantial in relation to the accuracy achievable in vertical network measurements.

As can be observed from graphs, benchmarks fixed on buildings masonry show divergent variation with respect to cumulate rainfall: as an example, under equal weather conditions and similar farm building structures, points BMB4 and BMB5 follow uncorrelated behaviours. In a similar way even the points fixed on concrete castings show diversified behaviours in relation to their distance from soil surface not sealed by the artificial covering.

Conversely, observing the comparison between the movements of benchmarks fixed at known depth, shown in figure 11 , the effect induced by cumulate rainfall decreases rapidly with depths. Therefore, in fine-grained soils benchmarks fixed at depth greater than 1-2 m appear to be considered more reliable also for monitoring movements of about $1 \mathrm{~mm}$, in relation to the swelling effects occurred in the first meters of soil imbibition.

\section{CONCLUSION}

In this study levelling data from 11 measurement repetitions, carried out approximately every one/two weeks over three months, were examined. The test field was realised to investigate the vertical movements induced by possible soil swelling after rainfall. 


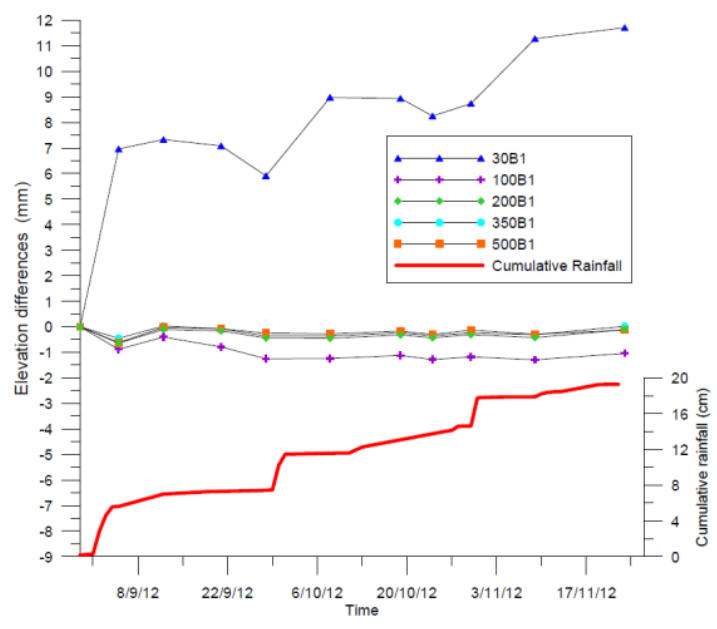

Figure 11. Elevation differences for benchmarks fixed in soil: comparison between the behaviours of neighbour benchmarks founded at different depths, with respect to first epoch.

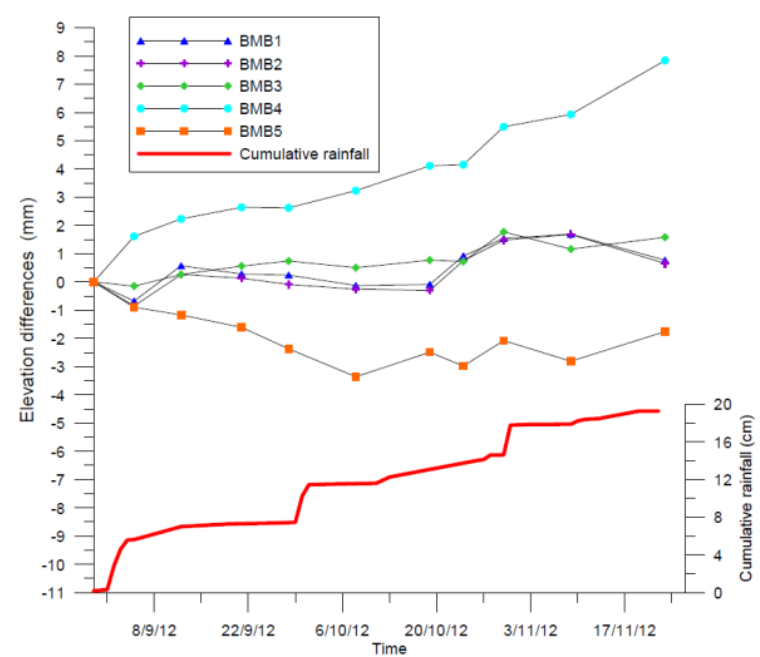

Figure 12. Elevation differences for benchmarks fixed in masonry of old buildings at unknown foundation depth, with respect to first epoch.

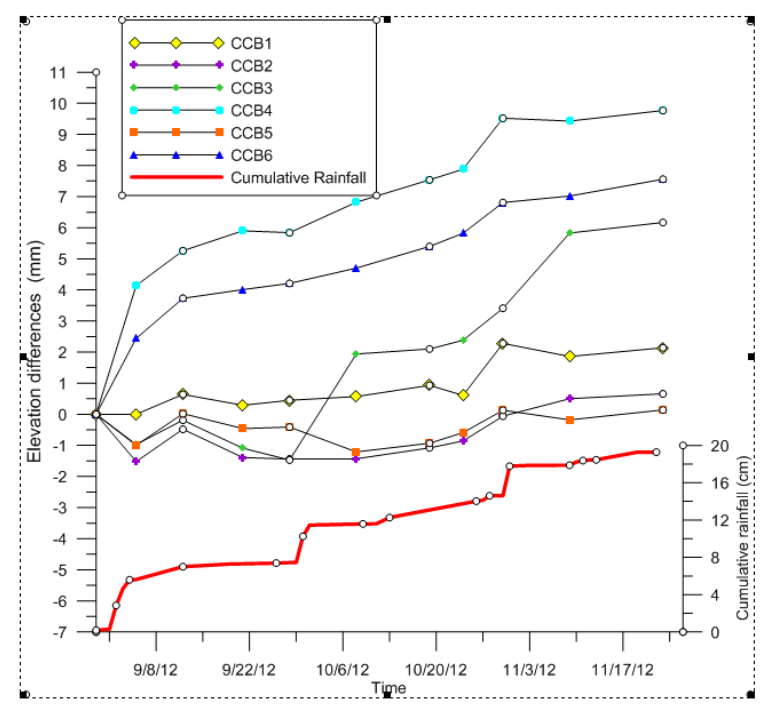

Figure 13. Elevation differences for benchmarks fixed in concrete casting over soil with respect to first epoch.
The benchmarks fixed in the soil at $0.3 \mathrm{~m}, 1 \mathrm{~m}, 3.5 \mathrm{~m}, 5 \mathrm{~m}$ showed significant differential motions, in the order of several millimetres, with a markedly different behaviour with depth.

To avoid interpreting as movements simple artefacts due to local changes of soil water contents induced by rainfall, it is advisable to refer the measurements of levelling networks to benchmarks fixed at least at 1-2 m depths. Conversely it is much harder to provide information on the materialization of benchmarks fixed on existing structures, because for a reliable interpretation of vertical movements induced by cumulative rainfall and the overall soil water content, it would be necessary to make assumptions on the depth of the foundations, often not known, or it would be necessary to consider the effects induced by the presence of structures preventing the soil watering, really difficult to quantify.

The experiment showed interesting results, highlighting that in presence of unsaturated soil the cumulative rainfall induces height variations in the soil surface far from negligible. Obviously, these relatively rapid movements of the soil surface are particularly insidious in case the repetition of measures are spaced in time and limited in number. In fact, in presence of time series of frequent observations, this effect mainly represents an increase of noise around the trend lines, while in the case of isolated measures this effect can lead to highly unreliable conclusions.

\section{REFERENCES}

\section{References from Journals:}

Beavan, J., 2005. Noise properties of continuous GPS data from concrete pillar geodetic monuments in New Zealand and comparison with data from U.S. deep drilled braced monuments, J Geophys Res, 110, B08410.

Dal Moro, G., Zadro, M., 1998. Subsurface Deformations Induced by Rainfall and Atmospheric Pressure: Tilt/Strain Measurements in NE-Italy Seismic Area. Earth Planet. Sci. Lett. 164, 193-203.

Dong, D., Fang, P., Bock, Y., Cheng,M. K., Miyazaki, S., 2002. Anatomy of apparent seasonal variations from GPSderived site position time series, J Geophys Res, 107(B4), 2075.

Romagnoli, C., Zerbini, S., Lago, L., Richter, B., Simon, D., Domenichini, F., Elmi, C., Ghirotti, M., 2003. Influence of soil consolidation and thermal expansion effects on height and gravity variations, J Geodyn, 35, 521-539.

Sarti, P., Abbondanza, C., Legrand, J., Bruyninx, C., Vittuari, L., Ray, J., 2013. Intra-site motions and monument instabilities at Medicina ITRF co-location site. Geophys. J. Int. Advance Access. 10 pp.

Wyatt F., 1989. Displacement of Surface Monuments: Vertical Motion, J Geophys Res, 94(B2), 1655-1664.

\section{References from Other Literature:}

Johnson, H. O., Agnew, D.C., 2000. Correlated noise in geodetic time series, Final Tech. Rep. FTR-1434-HQ-97GR-03155, 18 pp., U. S. Geol. Surv., Reston, Va.

\section{References from websites:}

UNAVCO Knowledge: http://facility.unavco.org/kb/questions /300/Deep+Drilled+Braced+Monument+Overview 